\title{
Predator or plant pest? Observations on Parascolothrips priesneri Mound (Thysanoptera: Thripidae) in Israeli apple orchards
}

\author{
T. Ben-David, ${ }^{1}$ L.A. Mound ${ }^{2}$ \\ ${ }^{1}$ Plant Protection and Inspection Services, Bet Dagan, Israel; ${ }^{2}$ Australian National Insect Collection \\ - Commonwealth Scientific and Industrial Research Organisation, Canberra, Australia
}

\begin{abstract}
Field and laboratory observations on Parascolothrips priesneri failed to confirm previous reports that this insect is a predator of mites, but instead demonstrated that it can cause severe feeding damage to the leaves of apple trees.
\end{abstract}

\section{Introduction}

The black and white winged thrips, Parascolothrips priesneri Mound (Figure 1A), was described originally from specimens collected on the leaves of apple trees in Iraq (Mound, 1967). The collector of this thrips in Iraq reported that it fed on the spider mite Tetranychus atlanticus (now considered synonymous with $T$. turkestani), a common pest of apple orchards in the Middle East. In Israel, Halperin \& zur Strassen (1981) collected in May 1974 two females of $P$. priesneri from the leaves of the rosaceous ornamental shrub, Pyracantha crenato-serrata in the coastal plain. These authors listed this thrips as predaceous on mites and its host plants as Lignaceous species of Rosaceae and Punica granatum. Later publica-

Correspondence: Tselila Ben-David, Plant Protection and Inspection Services, PO Box 78, Bet Dagan, 50250 Israel.

E-mail: zlilabd@gmail.com

Key words: Parascolothrips priesneri; Malus domestica; Israel; leaf damage.

Acknowledgements: we are particularly grateful for the help and advice of two anonymous referees, also to Dov Openheim and Yoni David for showing the orchard damage and sharing information from their insecticide trials for the control of thrips.

Received for publication: 25 September 2015.

Accepted for publication: 26 October 2015.

(C) Copyright T. Ben-David and L.A. Mound, 2016

Licensee PAGEPress, Italy

Journal of Entomological and Acarological Research 2016; $48: 5532$

doi:10.4081/jear.2016.5532

This article is distributed under the terms of the Creative Commons Attribution Noncommercial License (by-nc 4.0) which permits any noncommercial use, distribution, and reproduction in any medium, provided the original author(s) and source are credited. tions (zur Strassen, 2003; Mirab-balou et al., 2013) continued to refer to $P$. priesneri as a predator of spider mites. However, to date, there are no publications on the biology of this thrips and its effectiveness as a mite predator, not even reliable observations of adults or larvae actually feeding on mites.

\section{Materials and methods}

The role of $P$. priesneri in agroecosystems was examined in orchards and in laboratory. Direct observations before and after pesticide treatment were carried out, including observations on the reaction of this thrips to the presence of spider mites, Tetranychus urticae.

\section{Results}

\section{Recent case study}

In November 2007, we found one female of $P$. priesneri on apple seedlings infested with spider mites in a greenhouse at Bet Dagan on the coastal plain of Israel. At that time, another female of $P$. priesneri was found on Lycianthes rantonnetii in a garden at Gan-Yavne, about $15 \mathrm{~km}$ south of Bet Dagan. In September 2011, apple growers from northern Israel reported hot spots of damaged apple trees in orchards with the varieties Golden Delicious and Pink Lady. Affected trees had brown leaves and suffered premature fall of leaves (Figure 1D and E). On these damaged leaves we found $P$. priesneri in high numbers, both adults and larvae (Figure $1 \mathrm{~B}$ and $\mathrm{C}$ ), but no mites were found on the leaves. The affected orchard had been treated with the miticide Acequinocyl to control spider mites 3 months before the damage was noticed (14.vii.2011). An integrated pest management (IPM) was practiced at the affected orchard, and the high populations of $P$. priesneri developed after the cessation of broad-spectrum pesticides application. In 2012, $P$. priesneri reappeared at the same orchard but no damage was observed. During harvest at the end of September 2013, high thrips populations were found in another plot of the variety Golden Delicious. At that time, these thrips were also found in another orchard, $50 \mathrm{~km}$ to the west, on the variety Pink Lady before harvest. In this orchard, growers just started practicing IPM and stopped applying broad-spectrum insecticides. When damage was noted, the affected trees were treated with the insecticide spinetoram. However, this treatment resulted in only partial control of the thrips. Neighboring trees of the variety Golden Delicious that were not treated had as many as 50 thrips per leaf. In June and July 2014, adults of $P$. priesneri were found at the two sites where infestation occurred in the previous year. 

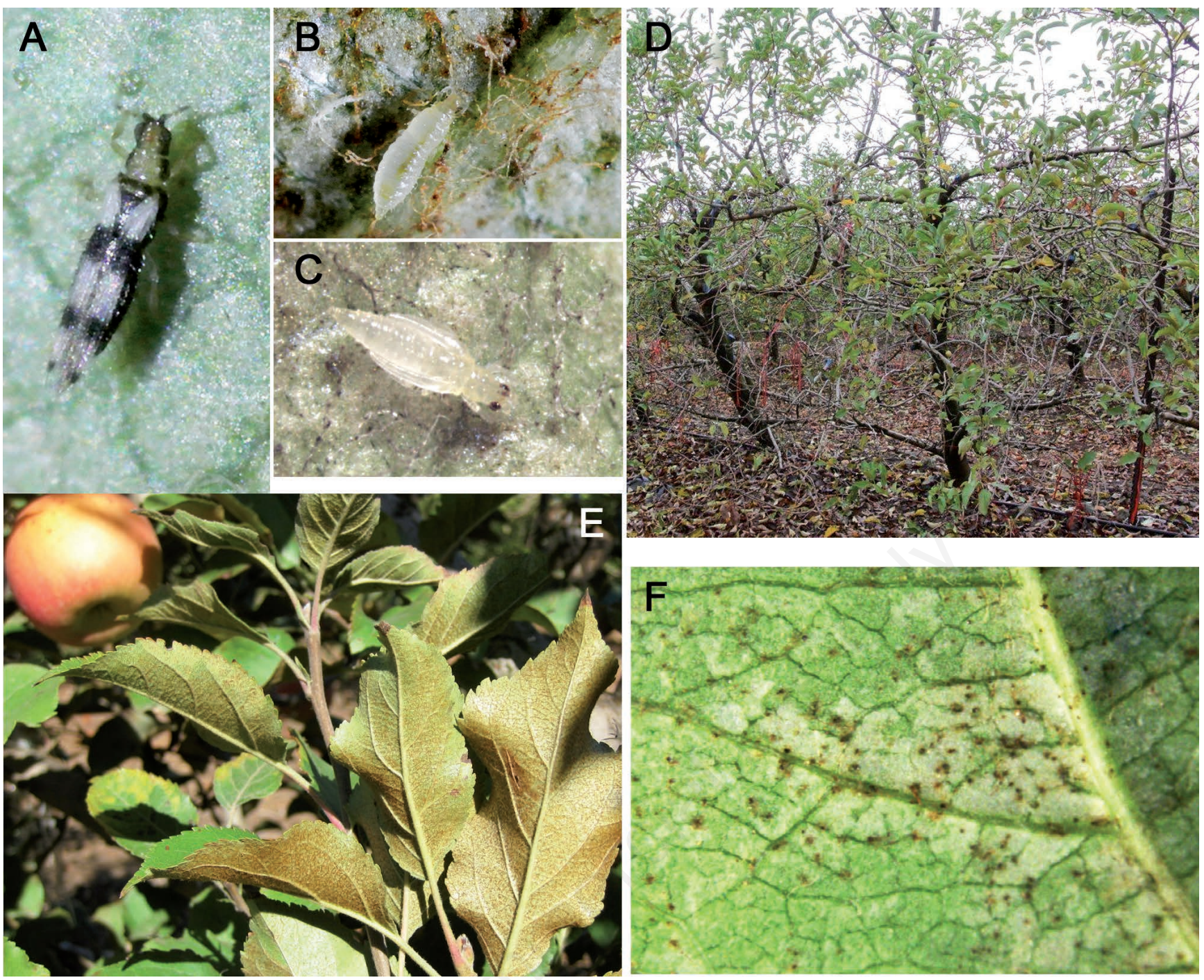

Figure 1. A) Parascolothrips priesneri female. B) $P$. priesneri second instar (photo by courtesy of Yehuda Weinberg). C) $P$. priesneri pre pupa. D) Leaf fall in a thrips infested plot in an apple orchard (var Golden Delicious at Ramat Magshimim, 2013). E) The underside of apple leaves infested with the thrips (var Pink Lady at Bar-Am, 2013; photo by courtesy of Dr. Hayim Reuveni). F) Silver streaked apple leaf caused by thrips feeding.

One orchard was treated on 8.vii.2014 with imidacloprid (drench) to control aphids. Following this treatment, no thrips or damage were noted. The other orchard had a premature leaf fall starting at midAugust in the same plot as a year before. In September 2014, P. priesneri caused much damage to Anna variety after harvest, $200 \mathrm{~km}$ south of the northern infested orchards. Thus, it appears that $P$. priesneri is widespread in apple orchards in Israel, and commonly associated with leaf damage.

\section{Thrips damage}

Apple leaves damaged by the spider mites T. turkestani and Panonychus ulmi have small white spots on both sides of the leaf and they turn chlorotic with time. High infestations of these mites can cause premature leaf drop in apple trees. In contrast, leaf damage due to the thrips $P$. priesneri is mainly on the underside of leaves as light green to silvery streaks (Figure 1F), and damaged leaves turn brown with time (Figure 1E). Infested trees become dull in appearance due to premature leaf drop (Figure 1D). The above field observations suggest that when large populations of $P$. priesneri develop on apple trees they can cause feeding damage to the leaves of apple trees. Also, this thrips can infest apple trees heavily even in the absence of spider mites. Thus, it appears that this thrips is not an obligate predator. However, the possibility remains that it may be a facultative predator, with similar feeding habits to other pest thrips like Thrips tabaci, Frankliniella occidentalis and Fr. schultzei (Kirk, in Lewis 1997).

\section{Laboratory studies}

In order to study the feeding habits of $P$. priesneri we attempted to rear it in the laboratory $\left(25 \pm 2^{\circ} \mathrm{C}\right)$ on various diets in 2013 and 2014 under natural shortening days (12 $\mathrm{h}$ in October to $10 \mathrm{~h}$ in December). Adult thrips survived for two weeks on detached green bean leaves and pods with and without spider mites (T. urticae) but did not produce viable offspring. On fresh apple leaves adult thrips survived for two months with and without spider mites but did not produce viable offspring. When adult thrips were provided with spider mites eggs and larvae they showed no interest in them. 


\section{Conclusions}

Our observations suggest that $P$. priesneri is not an effective predator of spider mites. Moreover, we did not observe this thrips feeding on mites, and there remains no clear evidence that the species is ever predatory in its feeding habits. On the other hand, it clearly feeds on leaves and under certain conditions can become a pest of apple trees. Therefore, we recommend including this thrips among the other pests that should be scouted for in apple orchards in Israel and neighboring countries.

\section{References}

HALPERIN J., ZUR STRASSEN R., 1981 - Thysanoptera of forest and ornamental woody plants in Israel with a list of the species recorded from Israel. - Israel J. Entomol. 15: 21-33.

KIRK W.D.J., 1997 - Feeding. Chapter 4. In: LEWIS T., ed. Thrips as crop pests. - CAB International, Wallingford: 119-174.

MIRAB-BALOU M., MINAEI K., CHEN X.X., 2013 - An illustrated key to the genera of Thripinae (Thysanoptera, Thripidae) from Iran. Zookeys 317: 27-52.

MOUND L.A., 1967 - A new genus and species of Thysanoptera predatory on mites in Iraq. - Bull. Entomol. Res. 57: 315-319.

ZUR STRASSEN R., 2003 - Die terebranten Thysanopteren Europas und des Mittelmeer-Gebietes. - Die Tierwelt Deutsch. 74: 1-271. 